Original article

\title{
Variation of genes encoding KAT1, AADAT and IDO1 as a potential risk of depression development
}

\author{
Paulina Wigner ${ }^{\mathrm{a}}$, Piotr Czarny ${ }^{\mathrm{b}}$, Ewelina Synowiec ${ }^{\mathrm{a}}$, Michał Bijak $^{\mathrm{c}}$, Monika Talarowska ${ }^{\mathrm{d}}$, \\ Piotr Galecki ${ }^{\mathrm{d}}$, Janusz Szemraj ${ }^{\mathrm{b}}$, Tomasz Sliwinski ${ }^{\mathrm{a}, *}$ \\ a Laboratory of Medical Genetics, Faculty of Biology and Environmental Protection, University of Lodz, Lodz, Poland \\ ${ }^{\mathrm{b}}$ Department of Medical Biochemistry, Medical University of Lodz, Lodz, Poland \\ ${ }^{\mathrm{c}}$ Department of General Biochemistry, Faculty of Biology and Environmental Protection, University of Lodz, Lodz, Poland \\ d Department of Adult Psychiatry, Medical University of Lodz, Lodz, Poland
}

\section{A R T I C L E I N F O}

Article history:

Received 31 January 2018

Received in revised form 30 April 2018

Accepted 2 May 2018

Available online 25 May 2018

\section{Keywords:}

Depression

Tryptophan catabolites pathway

Single nucleotide polymorphism

Indoleaminepyrrole 2,3-dioxygenase

Kynurenine aminotransferase

\begin{abstract}
A B S T R A C T
Numerous data suggests that the disorders of tryptophan catabolites (TRYCATs) pathway, including a decreased level of tryptophan or evaluated concentration of harmful TRYCATs - kynurenine, quinolinic acid, 3-hydroxyanthranilic acid, 3-hydroxytryptophan - may cause the occurrence of DD symptoms. In this work, we assessed the relationship between single-nucleotide polymorphisms (SNPs) of KAT1, KAT2 and IDO1 gene encoding, and the risk of depression development. Our study was performed on the DNA isolated from peripheral blood of 281 depressed patients and 236 controls. We genotyped, by using TaqMan probes, four polymorphisms: c.*456G > A of KAT1 (rs10988134), c.975-7T > C of AADAT (rs1480544), c.-1849C > A (rs3824259) and c.-1493G > C(rs10089084)of ID01. We found that only the A/ A genotype of c. ${ }^{*} 456 \mathrm{G}>\mathrm{A}-K A T 1$ (rs10988134) increased the risk of depression occurrence. Interestingly, when we stratified the study group according to gender, this relationship was present only in male population. However, a gene-gene analysis revealed a link between the $\mathrm{T} / \mathrm{T}-\mathrm{C} / \mathrm{C}$ genotype of c.975-7T > C - AADAT (rs1480544)or c.-1493G > C - IDO1 (rs10089084) and C/C-C/A genotype of c.9757T > C - AADAT (rs1480544)and c. $-1849 \mathrm{C}>\mathrm{A}-I D 01$ (rs3824259) and the disease. Moreover, we found, that the c.975-7T > C - AADAT and c. *456G > A KAT1 (rs10988134) polymorphisms may modulate the effectiveness of selective serotonin reuptake inhibitors therapy. Concluding, our results confirm the hypothesis formulated in our recently published article that the SNPs of genes involved in TRYCATs pathway may modulate the risk of depression. This provides some further evidence that the pathway plays the crucial role in development of the disease.
\end{abstract}

(c) 2018 Elsevier Masson SAS. All rights reserved.

\section{Introduction}

Depression (a depressive disorder, DD) is the most common mental disorder. All around the world, 300 million people suffer from DD [1]. Moreover, by 2020, depression will have become the second health and economic problem, second only to the ischemic heart disease [2]. Additionally, about $1 / 3$ patients does not respond to the conventional therapy, and untreated or inappropriately treated depression may lead to suicide attempts [3]. Previous studies showed that the DD is regarded as multi-casual disease and its pathology remains unclear [4-7]. Additionally, depression is associated with numerous somatic disease - it increases the risk of

\footnotetext{
* Corresponding author at: 141/143 Pomorska Street, 90-236. Lodz, Poland. E-mail address: tomasz.sliwinski@biol.uni.lodz.pl (T. Sliwinski).
}

developing the atherosclerotic heart disease, type 2 diabetes mellitus, cancer - and increases mortality rates [8-10]. Furthermore, recent studies showed, that DD occurrence is also strongly associated with obesity [11-14]. Interestingly, obese patients, similarly to depressed patients, were characterized by an imbalance of tryptophan catabolites (TRYCATs) pathway [15]. Our earlier study of single nucleotide polymorphisms (SNPs) of genes encoding tryptophan hydroxylase suggests that the tryptophan metabolism may play the key role in the pathophysiology of DD [16]. Another study showed that a decreased level of tryptophan or an elevated concentration of harmful TRYCATs, i.e. kynurenine, quinolinic acid, 3-hydroxyanthranilic acid, 3-hydroxytryptophanmay cause the DD symptoms to surface [6]. Although tryptophan is converted into toxic kynurenine, it also is a precursor of serotonin (5-HT) and melatonin - a main neurotransmitter that regulates the mood [17]. The first step of TRYCATs pathway, which is degradation 
of tryptophan to $\mathrm{N}$-formylkynurenine, is catalysed by tryptophan 2,3-dioxygenase (TDO) or indoleamine-pyrrole-2,3-dioxygenase (IDO). There are rate-limiting enzymes of this pathway. TDO is expressed in liver and converts tryptophan only, whereas IDO is expressed in placenta, lungs, brain, blood - and, aside from tryptophan, it also metabolizes melatonin and serotonin $[18,19]$. Furthermore, the activity of IDO may be regulated by cytokines, whereas TDO does not depend on this regulation. Pro-inflammatory cytokines - interferon- $\gamma$ (INF $\gamma$ ), interferon- $\alpha$ (INF $\alpha$ ), and tumour necrosis factor- $\alpha$ (TNF $\alpha)$ - may act as potent activators of IDO. On the other hand, the anti-inflammatory cytokines may be inhibitors of the enzyme [20-22]. Clinical trials showed that the activity of IDO may be assessed by the examination of kynurenine/ tryptophan ratio or by expression level of $I D O[5,6]$. The previous studies suggest that an increased activity of IDO and TDO may be an associated with occurrence of the depressive-like behaviours $[23,24,5,6]$. Moreover, an elevated kynurenine/tryptophan ratio may cause a development of anhedonia, which is the primary symptom of depression [25]. Animal studies confirmed that depression may be associated with an increased IDO expression/ activity and levels of kynurenine, 5-hydroxykynurenine, quinolinic acid in brain areas, i.e. hippocampus, hypothalamus and amygdala [26-29]. Moreover, the IDO activation and serum level of the harmful TRYCATs were associated with the onset and severity of the disease symptoms [30-33]. Interestingly, the study showed that the female patients with the DD were characterized by a higher serum concentration of IDO, TNF $\alpha$, INF $\gamma$ but by a lower level of serotonin when compared to healthy volunteers. Moreover, the levels of IDO and TNF $\alpha$ were decreased in patients after antidepressant therapy [34,35]. In the same study, Zoga et al. [34] found a strong positive correlation between the concentration of IDO and INF $\gamma$. Moreover, transcription of IDO1, a gene encoding one of the protein isoform, is strongly controlled by cytokines. The gene promoter contains multiple sequence elements that induction of responsiveness to type I (INF $\alpha$ and $-\beta$ ) and type II (INF $\gamma$ ) interferons $[36,37]$. Induction of the expression by the latter one is mediated by a signal transducer and activator of transcription 1 (STAT1) and INF-regulatory factor 1 [38]. Moreover, IDO metabolizes the serotonin degradation into $\mathrm{N}$-formyl-5-hydroxykynurenine; thus its over-expression results in a deficiency of the neurotransmitter [39]. Accordingly, the increased activity of the IDO and an impaired central serotonin system may lead to development of depression in patients with inflammatory disease $[40,41]$. The same study proved that glial cells secrete interleukin- 6 (IL-6), interleukin- 1 beta (IL-1 $\beta$ ), TNF- $\alpha$, and INF- $\gamma$ in response to injury and infection. Furthermore, it was found that DD could be potentially attributed to a hippocampal depletion of tryptophan, degradation of serotonin and increased level of kynurenine derived from serotonin degradation [6].

The next important step of TRYCATs pathway includes a conversion of kynurenine into kynurenic acid (enzyme kynurenine formamidase) or, alternatively, into 3-hydroxykynurenine (3-HK), enzyme - kynurenine aminotransferase, up to date, its four isoforms have been described: KAT1/glutamine transaminase $\mathrm{K}$ (GTK)/cysteine conjugate beta-lyase (CCBL) 1, KAT2/ aminoadipate aminotransferase (AADAT), KAT3/CCBL2 and KAT4/glutamicoxaloacetic transaminase (GOT) 2/mitochondrial aspartate aminotransferase (ASAT)or anthranilic acid (enzyme kynurenine hydroxylase) [42]. Subsequently, 3-HK can be metabolized by kynureninase to form 3-hydroxyanthranilic acid (3-HAA), which can be further metabolized to form the quinolinic acid (QUIA) [43]. Although QUIA is neurotoxic, it cannot penetrate the blood-brain barrier. On the other hand, kynurenine is not neuroactive; however it may cross the blood-brain barrier and it generates free-radical-producing 3-HK or 3-HAA or is converted to the glutamatergically-active QUIA [43]. The harmful actions of
TRYCATs may be related to an oxidative damage, inflammation, mitochondrial dysfunction, cytotoxicity, excitotoxicity, neurotoxicity and lowered neuroplasticity in central nervous system, e.g. 3-hydroxykynurenine may initiate neuronal apoptosis [44,45,6,7]. In contrast, some TRYCATs induce begin effects, e.g. kynurenic acid manifests antioxidant and neuroprotective properties which based on block N-methyl-D-aspartate (NMDA) receptors [44,45,5]. This acid is converted from kynurenine by kynurenineaminotransferase (KAT1 and KAT2/AADAT) Stone and Darlingtone, 2002. Therefore, the kynurenine/kynurenic acid (KYN/KA) ratio indicates a KAT activity (the ratio increase in inverse proportion to the KAT activity) and was found to be higher in depressed patients than controls [7]. Accordingly, an elevated expression of kynurenine aminotransferase in skeletal muscles can protect from depression [46]. Interestingly, the same study showed that physical exercise may be used as an alternative treatment of DD and that endurance exercise led to an increased expression of KAT in muscles, while the patients who were practising some sports/taking the training were characterized by an increased level of kynurenic acid in plasma. Another piece of evidence supporting involvement of TRYCATs pathway in depression development is the fact that abnormal activity of IDO may lead to impairment of serotonin metabolism and a decrease of melatonin level, and, in consequence, may trigger sleep disorders, all of these symptoms often present in the course of the disease [34]. Moreover, patients with depressive suicidal attempts suffer more frequently from severe insomnia than patents without the attempts [47].

The exact pathogenesis of the DD is unclear, genetic, environmental, and behavioral factors as well as interaction between them may be involved. Although the DD is recognized as a multifactorial disease, genetic factors may play the crucial role in its development, as was confirmed by segregation analyses, genetic epidemiological data and gene mapping studies. Several gene loci/chromosomal regions for DD have been mapped by genome-wide linkage analysis, including 12q23.3-q24.11 and 13q31.1-q31.3, 15q25.2 McGuffin et al., 2005, 3p21.1 Sullivian et al., 2013,19q12., 11p14.2, 8q22.2, 8q12.1, 8q23.3, 3p26.1, 2p25.1, 11p14.3, 6p22.3, 1q32.1, 3q26.1 (Shyn et al. 2011). These findings show a heterogeneous and complex genetic nature of the DD. Moreover, according to the study report, the genomic regions significantly associated with the DD were localized on chromosome $1,2,3,4,5,6,7,9,10,11,12,13,14,15,16,17,18,22$ Wray et al., 2017. Therefore, in this paper, we examine the link between single nucleotide polymorphisms (SNPs) of enzymes involved in TRYCATs pathway: c. ${ }^{*} 456 \mathrm{G}>\mathrm{A}$ of KAT1 (rs10988134, is located on 9q34.11), c.975-7T > C of AADAT (rs1480544, is located on 4q33), c.-1849C > A (rs3824259) and c.-1493G > C (rs10089084)of IDO1 (is located on $8 \mathrm{p} 11.21)$ and incidence of depression. Moreover, we detected differences between male or female groups in examined polymorphisms frequency. Interesting results were also obtained for the analysis an impact the single-nucleotide polymorphisms of genes encoding TRYCATs enzymes on effectiveness of antidepressant therapy.

\section{Materials and methods}

\subsection{Subjects}

281 patients with depression (age $49.53 \pm 10.18, \mathrm{n}$ male $=148, \mathrm{n}$ female $=133$ ) hospitalized at the Department of Adult Psychiatry of the Medical University of Lodz (Poland) and 236 healthy volunteers (age $53.19 \pm 12.61, \mathrm{n}$ male $=121, \mathrm{n}$ female $=115)$ participated in the study. The Table 1 . shows a detailed characteristic of depressed patients. All subjects in the control and depressed groups were native Poles from central Poland (not related), randomly selected without replacement sampling. All the participants had to meet 
Table 1

Detailed characteristic of patients taking part in the study.

\begin{tabular}{lcc}
\hline $\begin{array}{l}\text { Depression severity (HAMD } \\
\text { range of scores) }\end{array}$ & $\begin{array}{l}\text { Number of patients } \\
\text { before treatment }\end{array}$ & $\begin{array}{l}\text { Number of } \\
\text { patients after } \\
\text { treatment }\end{array}$ \\
\hline None (0-7) & 1 & 193 \\
Mild (8-16) & 35 & 85 \\
Moderate (17-23) & 94 & 3 \\
Severe ( $\geq 24)$ & 151 & 0 \\
Mean age of patients with first & & 30 \\
$\quad$ episode & & 50 \\
Mean age of patients with a & \\
further episode & 36 \\
Mean age of first episode (for all & & \\
patients) & Number of \\
Duration of disease from the & patients \\
first episode & 147 \\
$0-10$ Years & 56 \\
$11-20$ Years & 50 \\
$21-30$ Years & 26 \\
$31-40$ years & 2 \\
$\geq 41$ years & Number of \\
Number of episodes & patients \\
1 & 38 \\
2 & 88 \\
3 & 89 \\
4 & 53 \\
5 & 12 \\
6 & & 1 \\
\hline
\end{tabular}

the inclusion criteria outlined in ICD-10 [48]. The axes I and II disorders, other than the DD, severe and chronic somatic diseases, injuries of the central nervous system, inflammatory or autoimmune disorders and unwillingness to give informed consent were exclusion criteria. Moreover, familial prevalence of mental disorders other than recurrent depressive disorders was also a factor of exclusion from the examined groups. Standardized Composite International Diagnostic Interview (CIDI) served as the guide to conducting a medical history for all cases before the study began. Evaluation and classification of depression severity were based on the Hamilton Depression Rating Scale (HDRS) [49]. The intensity of DD symptoms was measured in the study according to the grades proposed by Demyttenaere and De Fruyt [50] before and after antidepressant therapy with a selective serotonin reuptake inhibitor (SSRI). The same psychiatrist examined each patient before the start of the study and after 8 weeks of pharmacotherapy. Participation in this study was voluntary. Its subjects were informed about the details of the study and assured of their voluntary participation in the experiment. Moreover, patients were guaranteed that their personal data would be kept secret before making a decision to participate in the study. During hospitalization, all the participants were treated according to antidepressant treatment standards. According to the protocol approved by the Bioethics Committee of the Medical University of Lodz (no. RNN/70/14/KE), all the subjects consented to participation in the study.

\subsection{Selection of single nucleotide polymorphism}

The public domain of the National Center for Biotechnology Information the Single Nucleotide Polymorphisms database (NCBI dbSNP) at http://www.ncbi.nlm.nih.gov/snp was used to identify potentially functional polymorphisms in genes encoding IDO and KAT. The four polymorphisms were chosen with a minor allele frequency (MAF) higher than 0.05 in the European population, respectively (submitter population ID: HapMap-CEU for both; http://www.ncbi.nlm.nih.gov/snp). The selection of studied polymorphisms was mainly determined by a potential biological significance - the localization of the SNPs was in the coding or regulatory regions of genes and might have functional meaning for transcription and protein function. The c. ${ }^{*} 456 \mathrm{G}>\mathrm{A}(\mathrm{rs} 10988134)$ polymorphism of KAT1 is localized in $3^{\prime}$ untranslated region and thec.975-7T > C (rs1480544) SNPis localized in intron of AADAT. The c. $-1849 \mathrm{C}>\mathrm{A}(\mathrm{rs} 3824259)$ and c.-1493G > C(rs10089084) polymorphisms are located near $5^{\prime}$ end of IDO1.

\subsection{DNA extraction}

We used the commercially available Blood Mini Kit (A\&A Biotechnology, Gdynia, Poland) to extract genomic DNA from venous blood of patients with depression and from all controls. DNA purity and concentration were determined by measuring e absorbance at 260 and $280 \mathrm{~nm}$. The sample of purified isolated DNA was stored at $-20 \mathrm{C}$ until further analysis.

\subsection{Genotyping}

The TaqMans SNP Genotyping Assay (Thermo Fisher Scientific, Waltham, Massachusetts, USA) and 2X Master Mix Takyon for Probe Assay - No ROX (Eurogentec, Liège, Belgium) were used to genotype the studied SNPs in the Bio-Rad CFX96 Real-Time PCR Detection System and analysed in the CFX Manager Software (BioRad Laboratories Inc., Hercules, California, USA). Theywere carried out the real-time polymerase chain reactions.

\subsection{Statistical analysis}

The SigmaPlot version 11.0 (Systat Software, Inc., San Jose, CA, USA), a statistical software package was used to the statistical analyses. The unconditional multiple logistic regression model was used to the evaluation of the correlation between case-control and each studied SNPs. This association was measured by the odds ratio (OR) with $95 \%$ confidence interval ( $95 \% \mathrm{CI}$ ). Additionally, the OR was adjusted for sex, since women have doubled risk of depression in comparison to men [51]. We also evaluated the correlation between the cases and controls for each studied polymorphisms in male/ female population by used to unconditional logistic regression model. Distribution of genotypes according to the year of the first episode of depression and severity of actual depressed episodes are showed as the median \pm inter-quartile range. The Shapiro-Wilks test was used to evaluate normality of the distribution. Next, the MannWhitney test or Student's $t$ test was used to estimate the significance of the difference between the analysed values.

\section{Results}

3.1. Single nucleotide polymorphisms of the gene encoding TRYCATs enzymes (KAT1, AADAT, IDO1) as the risk of the depressive disorder

Table 2 shows the distribution of genotypes and alleles in patients with the DD and in controls, which is in agreement with the Hardy-Weinberg equilibrium. We only found that the A/A genotype of the . $^{*} 456 \mathrm{G}>\mathrm{A}-$ KAT1 (rs10988134) may increase the risk of depression occurrence. No correlation was found between depressed patients and healthy volunteers in terms of distribution of genotypes of the left-over studied polymorphisms.

3.2. Single-nucleotide polymorphisms of the genes encoding TRYCATs enzymes and the age of the first episode of depression, and the severity classification on the Hamilton Depression Rating Scale

No significant differences was found between distribution of genotypes and the severity classification on the Hamilton 
Table 2

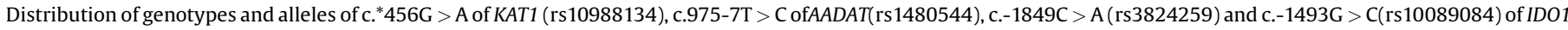
and incidence of depression.

\begin{tabular}{|c|c|c|c|c|c|c|c|c|}
\hline Genotype/Allele & Control $(n=236)$ & & Depression $(\mathrm{n}=281)$ & & Crude OR $(95 \% \mathrm{CI})^{\mathrm{a}}$ & $\mathrm{P}$ & Adjusted OR $(95 \% \mathrm{CI})^{\mathrm{a}}$ & $\mathrm{P}$ \\
\hline & Number & Frequency & Number & Frequency & & & & \\
\hline \multicolumn{9}{|c|}{$\mathrm{c}^{\mathrm{a}} 456 \mathrm{G}>\mathrm{A}-\mathrm{KAT1}(\mathrm{rs} 10988134)$} \\
\hline A/A & 9 & 0.038 & 23 & 0.082 & $2.266(1.027-4.998)$ & 0.043 & $2.269(1.029-5.007)$ & 0.042 \\
\hline $\mathrm{A} / \mathrm{G}$ & 77 & 0.326 & 95 & 0.338 & $1.066(0.738-1.540)$ & 0.733 & $1.065(0.737-1.539)$ & 0.736 \\
\hline $\mathrm{G} / \mathrm{G}$ & 150 & 0.636 & 163 & 0.580 & $0.782(0.548-1.117)$ & 0.176 & $0.783(0.548-1.117)$ & 0.177 \\
\hline \multicolumn{9}{|c|}{$\chi^{2}=3.659 ; p=0.056$} \\
\hline A & 95 & 0.201 & 141 & 0.251 & $1.323(0.991-1.766)$ & 0.058 & $1.323(0.991-1.766)$ & 0.058 \\
\hline G & 377 & 0.799 & 421 & 0.749 & $0.756(0.566-1.009)$ & 0.058 & $0.756(0.566-1.009)$ & 0.058 \\
\hline \multicolumn{9}{|c|}{ c.975-7T > C - AADAT (rs1480544) } \\
\hline $\mathrm{C} / \mathrm{C}$ & 67 & 0.284 & 62 & 0.221 & $0.709(0.475-1.059)$ & 0.093 & $0.710(0.475-1.060)$ & 0.094 \\
\hline $\mathrm{T} / \mathrm{C}$ & 116 & 0.492 & 142 & 0.505 & $1.065(0.753-1.506)$ & 0.723 & $1.063(0.751-1.504)$ & 0.732 \\
\hline $\mathrm{T} / \mathrm{T}$ & 53 & 0.225 & 77 & 0.274 & $1.299(0.868-1.945)$ & 0.204 & $1.301(0.869-1.949)$ & 0.201 \\
\hline \multicolumn{9}{|c|}{$\chi^{2}=3.283 ; p=0.070$} \\
\hline $\mathrm{C}$ & 250 & 0.530 & 266 & 0.473 & $0.796(0.622-1.020)$ & 0.071 & $0.796(0.622-1.019)$ & 0.071 \\
\hline $\mathrm{T}$ & 222 & 0.470 & 296 & 0.527 & $1.255(0.981-1.607)$ & 0.071 & $1.256(0.981-1.607)$ & 0.071 \\
\hline \multicolumn{9}{|c|}{ c. $-1849 C>A-I D 01($ rs3824259) } \\
\hline $\mathrm{C} / \mathrm{C}$ & 53 & 0.225 & 79 & 0.281 & $1.340(0.896-2.003)$ & 0.154 & $1.336(0.893-1.999)$ & 0.158 \\
\hline $\mathrm{C} / \mathrm{A}$ & 115 & 0.487 & 131 & 0.466 & $0.918(0.649-1.299)$ & 0.629 & $0.920(0.650-1.303)$ & 0.640 \\
\hline $\mathrm{A} / \mathrm{A}$ & 68 & 0.288 & 71 & 0.253 & $0.843(0.571-1.245)$ & 0.392 & $0.843(0.571-1.245)$ & 0.390 \\
\hline \multicolumn{9}{|c|}{$\chi^{2}=1.920 ; p=0.166$} \\
\hline $\mathrm{C}$ & 221 & 0.468 & 289 & 0.514 & $1.185(0.932-1.507)$ & 0.167 & $1.184(0.931-1.506)$ & 0.169 \\
\hline A & 251 & 0.532 & 273 & 0.486 & $0.844(0.664-1.073)$ & 0.167 & $0.845(0.664-1.074)$ & 0.169 \\
\hline \multicolumn{9}{|c|}{ c. $-1493 \mathrm{G}>\mathrm{C}-I D 01(\mathrm{rs} 10089084)$} \\
\hline $\mathrm{G} / \mathrm{G}$ & 39 & 0.165 & 46 & 0.164 & $0.997(0.625-1.591)$ & 0.991 & $0.996(0.624-1.589)$ & 0.986 \\
\hline $\mathrm{G} / \mathrm{C}$ & 125 & 0.530 & 136 & 0.484 & $0.833(0.588-1.178)$ & 0.301 & $0.833(0.589-1.179)$ & 0.303 \\
\hline $\mathrm{C} / \mathrm{C}$ & 72 & 0.305 & 99 & 0.352 & $1.233(0.852-1.786)$ & 0.267 & $1.233(0.851-1.786)$ & 0.268 \\
\hline \multicolumn{9}{|c|}{$\chi^{2}=0.592 ; p=0.442$} \\
\hline G & 203 & 0.430 & 228 & 0.406 & $0.905(0.703-1.167)$ & 0.442 & $0.905(0.702-1.166)$ & 0.440 \\
\hline $\mathrm{C}$ & 269 & 0.570 & 334 & 0.594 & $1.105(0.857-1.423)$ & 0.442 & $1.105(0.857-1.424)$ & 0.440 \\
\hline
\end{tabular}

$p<0.05$ along with corresponding Ors are in bold.

a OR adjusted for sex.

Depression Rating Scale. Neither did we observe the defferences in the distribution of genotypes and the age distribution of the first depressive episode (Supplementary Fig. 1 and Supplementary Fig. 2).

\subsection{Gene-gene interactions and the risk of depression}

Gene-gene interactions as a risk of depressive disorder is showed in Table 3 . We observed that the $\mathrm{T} / \mathrm{T}-\mathrm{C} / \mathrm{C}$ combined genotype of the c.975-71T > C - AADAT (rs1480544) and the c.1493G > C - IDO1 (rs10089084) more than doubled the risk of the DD occurrence, while the $\mathrm{C} / \mathrm{C}-\mathrm{C} / \mathrm{A}$ genotype of the c.975-7T $>\mathrm{C}-$ AADAT (rs1480544) and the c. C > A - IDO1(rs3824259) polymorphism combination reduced this risk. No statistical correlation was found between the combined genotypes of $c$. *456G > A (rs10988134) - KAT1 and c. -1849 C > A - IDO1 (rs3824259), c.*456G > A (rs10988134) - KAT1 and - IDO1 (rs10089084), c.975-7T > C - AADAT(rs1480544) and c. ${ }^{*} 456 \mathrm{G}>\mathrm{A}$ - KAT1 (rs10988134) and development of depression.

\subsection{Haplotypes and the risk of occurrence of depression}

We also analysed if the haplotypes of the studied polymorphisms is associated with occurrence of depression and the results are presented in Table 4. We found that the CC haplotype of the c.$1849 \mathrm{C}>\mathrm{A}-\mathrm{ID01}$ (rs3824259) and c.-1493G > C - IDO1 (rs10089084) polymorphism increased the risk of depression occurrence. However, we did not observe a connection between depression and other haplotypes of the studied polymorphisms ofID01gene.

3.5. Single-nucleotide polymorphisms of genes encoding enzymes of TRYCATs pathway depression occurrence in male and female population

Kessler [51] observed that women were exposed to a doubled risk of depression when compared to men. Therefore, we studied the connection between the depression occurrence in male or female groups and all examined polymorphisms (Table 5). On the one hand, we found that the A/A genotype and A allele of the $c$. *456G > A - KAT1 (rs10988134) were association with an increased risk of depression development in male population, while in female population we did not observe this correlation. On the other hand, the $G / G$ genotype and the $G$ allele of the same polymorphism were linked to a lower risk in male population, while this dependence was not observed in females. Moreover, we investigated the relationship between the distribution of genotypes or alleles and gender in patients with depression but this association was not found for all the studied polymorphisms (data not published).

\subsection{Single-nucleotide polymorphisms of genes encoding TRYCATs enzymes of and effectiveness of treatmentof the depression}

We also study an impact the single-nucleotide polymorphisms of genes encoding TRYCATs enzymes on the effectiveness of 
Table 3

Gene-gene interactions of studied polymorphisms and the risk of DD.

\begin{tabular}{|c|c|c|c|c|c|c|c|c|}
\hline \multirow[t]{2}{*}{ Combined genotype } & \multicolumn{2}{|c|}{ Control $(n=236)$} & \multicolumn{2}{|c|}{ Depression $(n=281)$} & \multirow[t]{2}{*}{ Crude OR $(95 \% \mathrm{CI})^{\mathrm{a}}$} & \multirow[t]{2}{*}{$p$} & \multirow[t]{2}{*}{ Adjusted OR $(95 \% \mathrm{CI})^{\mathrm{a}}$} & \multirow[t]{2}{*}{$p$} \\
\hline & Number & Frequency & Number & Frequency & & & & \\
\hline \multicolumn{9}{|c|}{ c. $^{\mathrm{a}} 456 \mathrm{G}>\mathrm{A}(\mathrm{rs} 10988134)-K A T 1$ and c. $-1849 \mathrm{C}>\mathrm{A}-\mathrm{IDO1}(\mathrm{rs} 3824259)$} \\
\hline $\mathrm{A} / \mathrm{A}-\mathrm{C} / \mathrm{C}$ & 1 & 0.004 & 7 & 0.025 & $6.004(0.733-49.151)$ & 0.095 & $5.953(0.726-48.807)$ & 0.097 \\
\hline $\mathrm{A} / \mathrm{A}-\mathrm{C} / \mathrm{A}$ & 3 & 0.013 & 11 & 0.039 & $3.164(0.872-11.478)$ & 0.080 & $3.185(0.877-11,561)$ & 0.078 \\
\hline $\mathrm{A} / \mathrm{A}-\mathrm{A} / \mathrm{A}$ & 5 & 0.021 & 5 & 0.18 & $0.837(0.239-2.927)$ & 0.781 & $0.843(0.241-2.949)$ & 0.789 \\
\hline $\mathrm{G} / \mathrm{A}-\mathrm{C} / \mathrm{C}$ & 13 & 0.055 & 28 & 0.100 & $1.898(0.960-3.755)$ & 0.065 & $1.890(0.955-3.744)$ & 0.068 \\
\hline $\mathrm{G} / \mathrm{A}-\mathrm{C} / \mathrm{A}$ & 40 & 0.169 & 44 & 0.157 & $0.910(0.570-1.453)$ & 0.692 & $0.911(0.570-1.455)$ & 0.696 \\
\hline $\mathrm{G} / \mathrm{A}-\mathrm{A} / \mathrm{A}$ & 24 & 0.101 & 23 & 0.082 & $0.787(0.432-1.435)$ & 0.435 & $0.789(0.433-1.438)$ & 0.439 \\
\hline $\mathrm{G} / \mathrm{G}-\mathrm{C} / \mathrm{C}$ & 39 & 0.165 & 44 & 0.157 & $0.938(0.586-1.501)$ & 0.789 & $0.939(0.586-1.503)$ & 0.792 \\
\hline $\mathrm{G} / \mathrm{G}-\mathrm{C} / \mathrm{A}$ & 72 & 0.305 & 76 & 0.270 & $0.844(0.576-1.238)$ & 0.386 & $0.846(0.577-1.240)$ & 0.390 \\
\hline $\mathrm{G} / \mathrm{G}-\mathrm{A} / \mathrm{A}$ & 39 & 0.165 & 43 & 0.153 & $0.913(0.569-1.464)$ & 0.705 & $0.910(0.567-1.461)$ & 0.696 \\
\hline \multicolumn{9}{|c|}{ c. $^{\mathrm{a}} 456 \mathrm{G}>\mathrm{A}(\mathrm{rs} 10988134)-K A T 1$ and c. $-1493 \mathrm{G}>\mathrm{C}-\mathrm{IDO1}(\mathrm{rs} 10089084)$} \\
\hline $\mathrm{G} / \mathrm{G}-\mathrm{G} / \mathrm{G}$ & 1 & 0.004 & 5 & 0.018 & $4.257(0.494-36.697)$ & 0.187 & $4.205(0.486-36.349)$ & 0.192 \\
\hline $\mathrm{G} / \mathrm{G}-\mathrm{G} / \mathrm{C}$ & 6 & 0.025 & 10 & 0.036 & $1.415(0.506-3.951)$ & 0.498 & $1.428(0.510-3.995)$ & 0.497 \\
\hline $\mathrm{G} / \mathrm{G}-\mathrm{C} / \mathrm{C}$ & 2 & 0.008 & 8 & 0.028 & $3.429(0.721-16.304)$ & 0.121 & $3.433(0.722-16.330)$ & 0.121 \\
\hline $\mathrm{G} / \mathrm{A}-\mathrm{G} / \mathrm{G}$ & 11 & 0.047 & 17 & 0.060 & $1.317(0.604-2.870)$ & 0.488 & $1.319(0.605-2.874)$ & 0.486 \\
\hline $\mathrm{G} / \mathrm{A}-\mathrm{G} / \mathrm{C}$ & 39 & 0.165 & 46 & 0.164 & $0.989(0.620-1.577)$ & 0.962 & $0.987(0.618-1.574)$ & 0.955 \\
\hline $\mathrm{G} / \mathrm{A}-\mathrm{C} / \mathrm{C}$ & 27 & 0.114 & 32 & 0.114 & $0.995(0.577-1.714)$ & 0.985 & $0.996(0.578-1.716)$ & 0.987 \\
\hline $\mathrm{A} / \mathrm{A}-\mathrm{G} / \mathrm{G}$ & 27 & 0.114 & 24 & 0.085 & $0.723(0.405-1.290)$ & 0.272 & $0.722(0.405-1.290)$ & 0.271 \\
\hline $\mathrm{A} / \mathrm{A}-\mathrm{G} / \mathrm{C}$ & 80 & 0.339 & 80 & 0.285 & $0.776(0.534-1.128)$ & 0.184 & $0.777(0.535-1.129)$ & 0.186 \\
\hline $\mathrm{A} / \mathrm{A}-\mathrm{C} / \mathrm{C}$ & 43 & 0.182 & 59 & 0.210 & $1.193(0.770-1.848)$ & 0.430 & $1.192(0.769-1.847)$ & 0.431 \\
\hline \multicolumn{9}{|c|}{ c.975-7T > C $-A A D A T($ rs1480544) and c. $-1493 G>C-I D 01($ rs10089084) } \\
\hline $\mathrm{C} / \mathrm{C}-\mathrm{G} / \mathrm{G}$ & 10 & 0.042 & 9 & 0.032 & $0.748(0.299-1.872)$ & 0.535 & $0.742(0.296-1.861)$ & 0.525 \\
\hline $\mathrm{C} / \mathrm{C}-\mathrm{G} / \mathrm{C}$ & 39 & 0.165 & 30 & 0.107 & $0.604(0.362-1.007)$ & 0.053 & $0.606(0.363-1.012)$ & 0.055 \\
\hline $\mathrm{C} / \mathrm{C}-\mathrm{C} / \mathrm{C}$ & 18 & 0.076 & 23 & 0.082 & $1.080(0.568-2.053)$ & 0.815 & $1.076(0.565-2.046)$ & 0.824 \\
\hline $\mathrm{T} / \mathrm{C}-\mathrm{G} / \mathrm{G}$ & 19 & 0.081 & 27 & 0.096 & $1.214(0.657-2.244)$ & 0.536 & $1.219(0.659-2.255)$ & 0.527 \\
\hline $\mathrm{T} / \mathrm{C}-\mathrm{G} / \mathrm{C}$ & 56 & 0.237 & 68 & 0.242 & $1.026(0.684-1.539)$ & 0.901 & $1.021(0.679-1.533)$ & 0.922 \\
\hline $\mathrm{T} / \mathrm{C}-\mathrm{C} / \mathrm{C}$ & 41 & 0.174 & 47 & 0.167 & $0.955(0.603-1.513)$ & 0.845 & $0.957(0.604-1.515)$ & 0.850 \\
\hline $\mathrm{T} / \mathrm{T}-\mathrm{G} / \mathrm{G}$ & 10 & 0.042 & 10 & 0.036 & $0.834(0.341-2.039)$ & 0.691 & $0.827(0.338-2.025)$ & 0.678 \\
\hline $\mathrm{T} / \mathrm{T}-\mathrm{G} / \mathrm{C}$ & 30 & 0.127 & 38 & 0.135 & $1.074(0.643-1.794)$ & 0.786 & $1.078(0.645-1.803)$ & 0.773 \\
\hline $\mathbf{T} / \mathbf{T}-\mathbf{C} / \mathbf{C}$ & 13 & 0.055 & 29 & 0.103 & $1.974(1.002-3.891)$ & 0.049 & $1.977(1.003-3.897)$ & 0.049 \\
\hline \multicolumn{9}{|c|}{ c.975-7T $>\mathrm{C}-A A D A T(\mathrm{rs} 1480544)$ and c. ${ }^{*} 456 \mathrm{G}>\mathrm{A}-K A T 1(\mathrm{rs} 10988134)$} \\
\hline $\mathrm{C} / \mathrm{C}-\mathrm{A} / \mathrm{A}$ & 2 & 0.008 & 6 & 0.021 & $2.553(0.510-12.768)$ & 0.254 & $2.527(0.504-12.664)$ & 0.260 \\
\hline $\mathrm{C} / \mathrm{C}-\mathrm{G} / \mathrm{A}$ & 24 & 0.102 & 19 & 0.068 & $0.641(0.342-1.201)$ & 0.165 & $0.640(0.341-1.200)$ & 0.164 \\
\hline $\mathrm{C} / \mathrm{C}-\mathrm{G} / \mathrm{G}$ & 41 & 0.174 & 37 & 0.132 & $0.721(0.445-1.169)$ & 0.184 & $0.723(0.446-1.173)$ & 0.189 \\
\hline $\mathrm{T} / \mathrm{C}-\mathrm{A} / \mathrm{A}$ & 5 & 0.021 & 7 & 0.025 & $1.180(0.370-3.768)$ & 0.780 & $1.194(0.373-3.819)$ & 0.765 \\
\hline $\mathrm{T} / \mathrm{C}-\mathrm{G} / \mathrm{A}$ & 32 & 0.136 & 56 & 0.199 & $1.587(0.988-2.548)$ & 0.056 & $1.584(0.986-2.545)$ & 0.057 \\
\hline $\mathrm{T} / \mathrm{C}-\mathrm{G} / \mathrm{G}$ & 79 & 0.335 & 79 & 0.281 & $0.777(0.534-1.131)$ & 0.188 & $0.775(0.532-1.128)$ & 0.183 \\
\hline $\mathrm{T} / \mathrm{T}-\mathrm{A} / \mathrm{A}$ & 2 & 0.008 & 10 & 0.036 & $4.317(0.937-19.903)$ & 0.061 & $4.324(0.938-19.935)$ & 0.060 \\
\hline T/T-G/A & 21 & 0.089 & 20 & 0.071 & $0.785(0.414-1.485)$ & 0.456 & $0.786(0.415-1.488)$ & 0.460 \\
\hline $\mathrm{T} / \mathrm{T}-\mathrm{G} / \mathrm{G}$ & 30 & 0.127 & 47 & 0.167 & $1.379(0.841-2.262)$ & 0.203 & $1.381(0.842-2.265)$ & 0.202 \\
\hline \multicolumn{9}{|c|}{ c.975-7T > C $-A A D A T($ rs1480544) and c. $-1849 C>A-I D O 1$ (rs3824259) } \\
\hline $\mathrm{C} / \mathrm{C}-\mathrm{C} / \mathrm{C}$ & 12 & 0.051 & 20 & 0.071 & $1.430(0.684-2.991)$ & 0.342 & $1.423(0.680-2.978)$ & 0.349 \\
\hline C/C-C/A & 40 & 0.169 & 26 & 0.093 & $0.500(0.295-0.847)$ & 0.010 & $0.501(0.295-0.850)$ & 0.010 \\
\hline $\mathrm{C} / \mathrm{C}-\mathrm{A} / \mathrm{A}$ & 15 & 0.064 & 16 & 0.057 & $0.890(0.430-1.840)$ & 0.752 & $0.886(0.428-1.834)$ & 0.745 \\
\hline $\mathrm{T} / \mathrm{C}-\mathrm{C} / \mathrm{C}$ & 29 & 0.123 & 40 & 0.142 & $1.185(0.709-1.978)$ & 0.517 & $1.181(0.707-1.973)$ & 0.526 \\
\hline $\mathrm{T} / \mathrm{C}-\mathrm{C} / \mathrm{A}$ & 53 & 0.225 & 63 & 0.224 & $0.998(0.659-1.511)$ & 0.992 & $0.997(0.658-1.509)$ & 0.988 \\
\hline $\mathrm{T} / \mathrm{C}-\mathrm{A} / \mathrm{A}$ & 34 & 0.144 & 39 & 0.139 & $0.957(0.583-1.573)$ & 0.864 & $0.958(0.583-1.574)$ & 0.866 \\
\hline $\mathrm{T} / \mathrm{T}-\mathrm{C} / \mathrm{C}$ & 12 & 0.051 & 19 & 0.068 & $1.354(0.643-2.850)$ & 0.425 & $1.360(0.646-2.864)$ & 0.419 \\
\hline $\mathrm{T} / \mathrm{T}-\mathrm{C} / \mathrm{A}$ & 22 & 0.093 & 42 & 0.149 & $1.709(0.988-2.956)$ & 0.055 & $1.710(0989-2.958)$ & 0.055 \\
\hline $\mathrm{T} / \mathrm{T}-\mathrm{A} / \mathrm{A}$ & 19 & 0.081 & 16 & 0.057 & $0.690(0.346-1.373)$ & 0.290 & $0.690(0.346-1.374)$ & 0.291 \\
\hline
\end{tabular}

$p<0.05$ along with corresponding Ors are in bold.

a OR adjusted for sex.

Table 4

Haplotypes of IDO1 and the risk of depression.

\begin{tabular}{|c|c|c|c|c|c|c|}
\hline \multirow[t]{2}{*}{ Haplotype } & \multicolumn{2}{|c|}{ Control $(n=236)$} & \multicolumn{2}{|c|}{ Depression $(n=281)$} & \multirow[t]{2}{*}{ Crude OR $(95 \% \mathrm{CI})$} & \multirow[t]{2}{*}{$\mathrm{p}$} \\
\hline & Number & Frequency & Number & Frequency & & \\
\hline \multicolumn{7}{|c|}{ c. $-1849 \mathrm{C}>\mathrm{A}-\mathrm{IDO1}(\mathrm{rs} 3824259)$ and c. $-1493 \mathrm{G}>\mathrm{C}-\mathrm{IDO1}(\mathrm{rs} 10089084)$} \\
\hline CG & 132 & 0.14 & 158 & 0.14 & $1.006(0.784-1.291)$ & 0.967 \\
\hline CC & 310 & 0.33 & 420 & 0.37 & $1.215(1.013-1.457)$ & 0.036 \\
\hline AG & 274 & 0.29 & 298 & 0.27 & $0.882(0.727-1.070)$ & 0.203 \\
\hline $\mathrm{AC}$ & 228 & 0.24 & 248 & 0.22 & $0.889(0.724-1.092)$ & 0.261 \\
\hline
\end{tabular}

$p<0.05$ along with corresponding ORs are in bold. 
Table 5

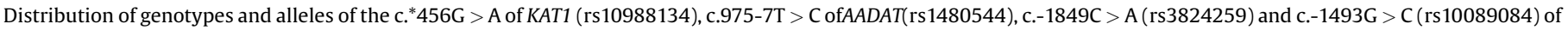
IDO1 and the risk of DD in male and female population.

\begin{tabular}{|c|c|c|c|c|c|c|c|c|}
\hline \multirow[t]{3}{*}{ Genotype/Allele } & \multicolumn{4}{|c|}{ MEN $(n=169)$} & \multicolumn{4}{|c|}{ WOMEN $(\mathrm{n}=248)$} \\
\hline & Control $(n=121)$ & Depression $(n=148)$ & Crude OR $(95 \% \mathrm{CI})^{*}$ & $\mathrm{p}$ & Control $(n=115)$ & Depression $(n=133)$ & Crude OR $(95 \% \mathrm{CI})^{*}$ & $\mathrm{p}$ \\
\hline & $\mathrm{N}$ (Freq.) & $\mathrm{N}$ (Freq.) & & & $\mathrm{N}$ (Freq.) & $\mathrm{N}$ (Freq.) & & \\
\hline \multicolumn{9}{|c|}{ c. ${ }^{*} 456 \mathrm{G}>\mathrm{A}-\mathrm{KAT1}(\mathrm{rs} 10988134)$} \\
\hline $\mathrm{A} / \mathrm{A}$ & $3(0.025)$ & $13(0.088)$ & 3.816 (1.061-13.718) & 0.040 & $6(0.052)$ & $10(0.075)$ & $1.489(0.524-4.232)$ & 0.455 \\
\hline $\mathrm{A} / \mathrm{G}$ & $37(0.306)$ & $54(0.365)$ & $1.318(0.790-2.199)$ & 0.290 & $40(0.348)$ & $41(0.308)$ & $0.845(0.496-1.438)$ & 0.534 \\
\hline G/G & $81(0.669)$ & $81(0.547)$ & $0.590(0.358-0.971)$ & 0.038 & $69(0.600)$ & $82(0.617)$ & $1.059(0.635-1.766)$ & 0.827 \\
\hline \multicolumn{5}{|c|}{$\chi^{2}=5.228 ; p=0.022$} & \multicolumn{4}{|c|}{$\chi^{2}=0.386 ; p=0.534$} \\
\hline A & $43(0.178)$ & $80(0.270)$ & 1.705 (1.124-2.589) & 0.012 & $52(0.226)$ & $48(0.180)$ & $1.027(0.683-1.542)$ & 0.899 \\
\hline G & $199(0.822)$ & $216(0.730)$ & $0.586(0.386-0.890)$ & 0.012 & $178(0.774)$ & $182(0.684)$ & $0.974(0.648-1.463)$ & 0.899 \\
\hline \multicolumn{9}{|c|}{ c.975-7T > C - AADAT (rs1480544) } \\
\hline $\mathrm{C} / \mathrm{C}$ & $33(0.273)$ & $32(0.216)$ & $0.742(0.424-1.299)$ & 0.296 & $34(0.296)$ & $30(0.226)$ & $0.701(0.396-1.240)$ & 0.222 \\
\hline $\mathrm{T} / \mathrm{C}$ & $59(0.488)$ & $80(0.541)$ & $1.221(0.754-1.977)$ & 0.417 & $57(0.496)$ & $62(0.466)$ & $0.901(0.546-1.487)$ & 0.684 \\
\hline $\mathrm{T} / \mathrm{T}$ & $29(0.240)$ & $36(0.243)$ & $1.029(0.587-1.804)$ & 0.921 & $24(0.208)$ & $41(0.308)$ & $1.649(0.920-2.954)$ & 0.093 \\
\hline \multicolumn{5}{|c|}{$\chi^{2}=2.552 ; p=0.110$} & \multicolumn{4}{|c|}{$\chi^{2}=2.877 ; p=0.090$} \\
\hline C & $125(0.517)$ & $144(0.486)$ & $0.883(0.625-1.248)$ & 0.481 & $125(0.543)$ & $107(0.402)$ & $0.729(0.513-1.036)$ & 0.078 \\
\hline $\mathrm{T}$ & $117(0.483)$ & $152(0.514)$ & $1.132(0.801-1.601)$ & 0.481 & $105(0.457)$ & $123(0.462)$ & 1.372() $0.966-1.951$ & 0.078 \\
\hline \multicolumn{9}{|c|}{ c. $-1849 \mathrm{C}>\mathrm{A}-\mathrm{IDO} 1(\mathrm{rs} 3824259)$} \\
\hline $\mathrm{C} / \mathrm{C}$ & $32(0.264)$ & $42(0.284)$ & $1.112(0.649-1.908)$ & 0.699 & $21(0.183)$ & $37(0.278)$ & $1.679(0.913-3.085)$ & 0.095 \\
\hline $\mathrm{C} / \mathrm{A}$ & $55(0.455)$ & $67(0.453)$ & $0.978(0.603-1.586)$ & 0.927 & $60(0.522)$ & $64(0.481)$ & $0.863(0.523-1.423)$ & 0.563 \\
\hline $\mathrm{A} / \mathrm{A}$ & $34(0.281)$ & $39(0.264)$ & $0.924(0.539-1.585)$ & 0.774 & $34(0.296)$ & $32(0.241)$ & $0.762(0.433-1.341)$ & 0.346 \\
\hline \multicolumn{5}{|c|}{$\chi^{2}=0.150 p=0.698$} & \multicolumn{4}{|c|}{$\chi^{2}=2.844 p=0.092$} \\
\hline $\mathrm{C}$ & $119(0.492)$ & $151(0.510)$ & $1.070(0.773-1.481)$ & 0.685 & $102(0.443)$ & $121(0.455)$ & $1.337(0.934-1.914)$ & 0.112 \\
\hline A & $123(0.508)$ & $145(0.490)$ & $0.935(0.675-1.294)$ & 0.685 & $128(0.557)$ & $109(0.410)$ & $0.748(0.522-1.070)$ & 0.112 \\
\hline \multicolumn{9}{|c|}{ c. $-1493 \mathrm{G}>\mathrm{C}-I D 01$ (rs10089084) } \\
\hline G/G & $20(0.165)$ & $26(0.176)$ & $1.076(0.568-2.041)$ & 0.822 & $19(0.165)$ & $20(0.150)$ & $0.902(0.455-1.789)$ & 0.768 \\
\hline $\mathrm{G} / \mathrm{C}$ & $63(0.521)$ & $71(0.480)$ & $0.849(0.525-1.375)$ & 0.504 & $62(0.539)$ & 65 (0.489) & $0.829(0.503-1.369)$ & 0.464 \\
\hline $\mathrm{C} / \mathrm{C}$ & $38(0.314)$ & $51(0.345)$ & $1.148(0.688-1.917)$ & 0.596 & $34(0.296)$ & $48(0.361)$ & $1.317(0.771-2.252)$ & 0.314 \\
\hline \multicolumn{5}{|c|}{$\chi^{2}=0.051 p=0.822$} & \multicolumn{4}{|c|}{$\chi^{2}=0.739 ; p=0.390$} \\
\hline G & $103(0.426)$ & $123(0.416)$ & $0.959(0.677-1.358)$ & 0.812 & $100(0.435)$ & $105(0.395)$ & $0.850(0.587-1.232)$ & 0.391 \\
\hline $\mathrm{C}$ & $139(0.574)$ & $173(0.584)$ & $1.043(0.737-1.477)$ & 0.812 & $130(0.565)$ & $161(0.605)$ & $1.176(0.812-1.704)$ & 0.391 \\
\hline
\end{tabular}

$p<0.05$ along with corresponding ORs are in bold.

antidepressant therapy (Table 6). Therefore, we divided the patients into two groups - those with the total score of Hamilton Rating Scale for Depression after treatment at the maximum of 7 points (marked as the effectiveness of antidepressant therapy) and those with the total score after treatment above 7 points (marked as an ineffective antidepressant therapy). We observed that the T/T genotype and the $\mathrm{T}$ allele of c.975-7T > C - AADAT(rs1480544) were related to a low effectiveness of the antidepressant therapy, while the $\mathrm{C}$ allele of the same polymorphism was positively correlated with a response to the applied SSRIs treatment. In the remaining cases, no correlation between SNP's occurrence and effectiveness of antidepressant treatment was found. Moreover, we showed some significant differences in the distribution of studied polymorphism genotypes and the percentage of Hamilton Rating Scale for Depression (Fig. 1). We found a difference in the percentage dispersion of Hamilton Rating Scale for Depression between the $A / A$ and $G / A, G / A$ and $G / G, A / A$ and $G / G$ genotypes of the c. ${ }^{*} 456 \mathrm{G}>\mathrm{A}$ KAT1 (rs10988134) polymorphism. Moreover, the disturbances were also observed between the $\mathrm{C} / \mathrm{C}$ and $\mathrm{T} / \mathrm{C}, \mathrm{T} / \mathrm{C}$ and $\mathrm{T} / \mathrm{T}, \mathrm{C} / \mathrm{C}$ and $\mathrm{T} / \mathrm{T}$ genotypes of the c.975-7T $>\mathrm{C}-\mathrm{AADAT}$ (rs1480544) polymorphism.

\section{Discussion}

Among various hypotheses explaining the pathogenesis of depression, impairments in TRYCATs pathway are now considered the major contributor to the development of DD. Elevated TRYCATs markers, i.e.quinolinic acid and kynurenine, were found in depressed patients and may be associated with some incorrect actions of the pathway enzymes [6,7]. In addition, our recent study demonstrated that SNPs of genes encoding two isoforms of tryptophan hydroxylase - an enzyme involved in the initial and rate-limiting step in the synthesis of serotonin and melatonin modulated the risk of depression Wigner et al., 2017b. In this paper, we reconfirmed that the TRYCATs pathway may be involved in pathogenesis of depression and we studied the relationship between four SNPs in KAT1,AADAT and IDO1 (two polymorphisms) genes and the risk of DD occurrence.

One of such key enzymes in TRYCATs pathway is kynurenine aminotransferase encoded by gene localized in 9q34.11.The enzyme plays many important roles, including, its cysteine conjugating betalyase activity, transaminase activity towards many amino acids and is involved in salvaging of $\alpha$-keto acids derived from essential amino acids [52]. As mentioned in the introduction, KAT catalyzes formation of kynurenic acid, which shows neuroprotective potency [7]. Hence, previous studies showed that the change of KAT level may be associated with neurodegenerative disorders [52]. The patients with Alzheimer's disease, Parkinson's disease, multiple sclerosis and Huntington's disease were characterized by a lower concentration of KAT in the central nervous system, while patients with HIV infection, Down's syndrome, amyotrophic lateral sclerosis, schizophrenia and epilepsy had increased level of the enzyme [52]. Up to date, no evidence has been presented to prove a relationship existing between polymorphisms of KAT1 and the development of neurodegeneration; however, it was established that the SNP analysed in the study causes a transition in the $3^{\prime}$ UTR region which may affect a KAT1 transcript stability [53], http//:genome.UCSC.edu). Additionally, other studies showed that the SNPs in this region of gene may affect mRNA half-life and degradation and, consequently, may lead to an increase or a decrease of gene expression [54,55]. Accordingly, 
Table 6

The impact of the single-nucleotide polymorphisms of genes encoding enzymes on the effectiveness of depression treatment.

\begin{tabular}{|c|c|c|c|c|c|c|}
\hline \multirow[t]{2}{*}{ Genotype/Allele } & \multicolumn{2}{|c|}{ Control $(n=236)$} & \multicolumn{2}{|c|}{ Depression $(\mathrm{n}=281)$} & \multirow[t]{2}{*}{ Crude OR $(95 \% \mathrm{CI})^{*}$} & \multirow[t]{2}{*}{$\mathrm{p}$} \\
\hline & Number & Frequency & Number & Frequency & & \\
\hline \multicolumn{7}{|c|}{ c. ${ }^{*} 456 \mathrm{G}>\mathrm{A}-\mathrm{KAT1}(\mathrm{rs} 10988134)$} \\
\hline $\mathrm{A} / \mathrm{A}$ & 13 & 0.081 & 6 & 0.083 & $1.020(0.372-2.798)$ & 0.970 \\
\hline $\mathrm{A} / \mathrm{G}$ & 53 & 0.329 & 25 & 0.342 & $1.061(0.592-1.904)$ & 0.842 \\
\hline $\mathrm{G} / \mathrm{G}$ & 94 & 0.588 & 43 & 0.581 & $0.941(0.537-1.648)$ & 0.832 \\
\hline \multicolumn{7}{|c|}{$\chi^{2}=0.032 ; p=0.859$} \\
\hline$\hat{A}$ & 79 & 0.245 & 37 & 0.253 & $1.040(0.677-1.597)$ & 0.858 \\
\hline G & 241 & 0.753 & 111 & 0.750 & $0.962(0.626-1.477)$ & 0.858 \\
\hline \multicolumn{7}{|c|}{ c.975-7T > C - AADAT (rs1480544) } \\
\hline $\mathrm{C} / \mathrm{C}$ & 38 & 0.236 & 12 & 0.164 & $0.637(0.311-1.305)$ & 0.218 \\
\hline $\mathrm{T} / \mathrm{C}$ & 88 & 0.547 & 34 & 0.466 & $0.723(0.415-1.259)$ & 0.252 \\
\hline $\mathbf{T} / \mathbf{T}$ & 34 & 0.213 & 28 & 0.378 & $2.113(1.154-3.870)$ & 0.015 \\
\hline \multicolumn{7}{|c|}{$\chi^{2}=5.363 ; p=0.021$} \\
\hline C & 164 & 0.509 & 58 & 0.397 & $0.618(0.408-0.934)$ & 0.023 \\
\hline $\mathbf{T}$ & 156 & 0.488 & 90 & 0.608 & $1.619(1.070-2.448)$ & 0.023 \\
\hline \multicolumn{7}{|c|}{ c. $-1849 \mathrm{C}>\mathrm{A}-\mathrm{IDO1}(\mathrm{rs} 3824259)$} \\
\hline $\mathrm{C} / \mathrm{C}$ & 51 & 0.317 & 17 & 0.233 & $0.655(0.347-1.237)$ & 0.192 \\
\hline $\mathrm{C} / \mathrm{A}$ & 68 & 0.425 & 35 & 0.473 & $1.162(0.667-2.026)$ & 0.596 \\
\hline $\mathrm{A} / \mathrm{A}$ & 41 & 0.255 & 22 & 0.301 & $1.263(0.684-2.330)$ & 0.456 \\
\hline \multicolumn{7}{|c|}{$\chi^{2}=1.534 ; p=0.215$} \\
\hline $\mathrm{C}$ & 170 & 0.531 & 69 & 0.466 & $0.791(0.545-1.148)$ & 0.217 \\
\hline A & 150 & 0.468 & 79 & 0.534 & $1.264(0.871-1.834)$ & 0.217 \\
\hline \multicolumn{7}{|c|}{ c. $-1493 G>C-I D 01($ rs 10089084$)$} \\
\hline $\mathrm{G} / \mathrm{G}$ & 29 & 0.180 & 12 & 0.164 & $0.895(0.428-1.873)$ & 0.769 \\
\hline $\mathrm{G} / \mathrm{C}$ & 77 & 0.481 & 34 & 0.459 & $0.878(0.504-1.529)$ & 0.646 \\
\hline $\mathrm{C} / \mathrm{C}$ & 54 & 0.335 & 28 & 0.384 & $1.233(0.694-2.189)$ & 0.475 \\
\hline \multicolumn{7}{|c|}{$\chi^{2}=0.416 ; p=0.519$} \\
\hline$\hat{G}$ & 135 & 0.422 & 58 & 0.392 & $0.878(0.591-1.305)$ & 0.520 \\
\hline $\mathrm{C}$ & 185 & 0.578 & 90 & 0.608 & $1.139(0.767-1.691)$ & 0.520 \\
\hline
\end{tabular}

$p<0.05$ along with corresponding ORs are in bold.
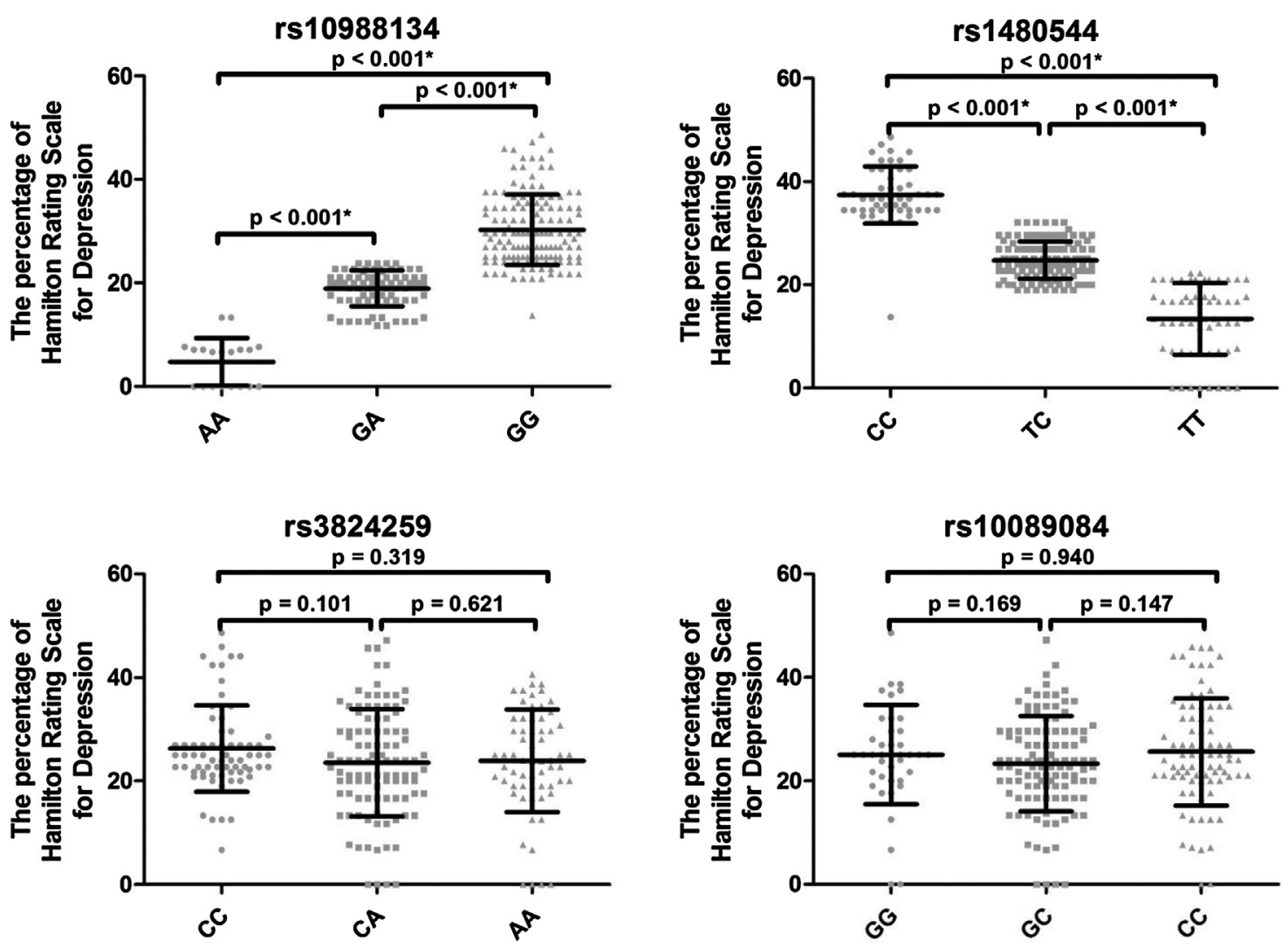

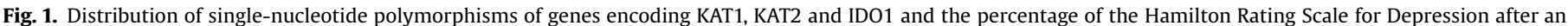
antidepressant therapy. Horizontal lines represent the median, while whiskers show the inter-quartile range. 
we were the first to show that the A/A genotype of c. ${ }^{*} 456 \mathrm{G}>\mathrm{A}-$ KAT1 (rs10988134) may increase the risk of depression occurrence $(p<0.05)$ (Table 2$)$. Thus, the A/A genotype may be associated with a decreased concentration or activity of KAT1 and may lead to an increase the level of neurotoxic kynurenine. Interestingly, when we stratified the study group by gender, this association was valid only for the male population $(p<0.05)$ (Table 5.). Although the consequence of this status is unknown, we may speculate that this differences may result from a different enzymes activity or concentration in men and in women group. The next studied polymorphism is located in locus 4q33 encoding AADAT (KAT2). The enzyme demonstrates the activity towards aminoadipate and $\alpha$-ketoglutarate and catalyzes transamination for a number of amino acids [52]. The c.975-71T $>\mathrm{C}-A A D A T$ ( $\mathrm{rs} 1480544) \mathrm{SNP}$ is in a putative exonic splicing silencers (ESSs), thus it may lead to some quantitative changes in the production of canonical mRNAs and peptide [56]. So far, only one study, carried out on the Brazilian population, showed that this SNP may have an impact on the phenotype - the C/T genotype of this SNP affected the host's expression of markers of the immune response to bacterial meningitis [42]. On the other hand, in our study we did not find any significant differences between depressed patients and healthy volunteers (Table 2). However, in gene-gene analyses, we found that the combined genotype of c.975-71T >C - AADAT(rs1480544) and c. $-1849 \mathrm{C}>\mathrm{A}$ (rs3824259) of IDO1 or c.-1493G > C of IDO1 (rs10089084) may modulate the risk of the depression development $(p<0.05)$ (Table 3$)$. Additionally, we showed that the T/T genotype is associated with poorer outcome of the SSRIs treatment $(p<0.05)$ (Table 6).This discovery can contribute to choosing the right personalized antidepressant treatment.

Lastly, we evaluated distribution of two SNPs encodes indoleamine 2,3-dioxygenase, which catalyzes the first and rate-limiting step in the TRYCATs pathway, leading to initiation of $\mathrm{N}$-formylkynurenine. Both polymorphism present near 5' (regulatory region) end of IDO1-gene located on chromosome 8p11. [57-59]. The previous studies suggested that the SNP in noncoding regions, including introns and regulatory regions, may cause an altered mRNA stability, degradation and expression, resulting in some changes in the activity of the final protein product [60-62]. Despite the potential changes caused by these polymorphisms, we did not detect the link between the SNPs occurrence and the development of depression (Table 2). Similarly, in a study of these polymorphisms frequency in patients with interferon-alpha-related depression in hepatitis $\mathrm{C}$ as compared to controls [63] its authors did not find any statistically significant results concerning thesetwo polymorphisms. On the other hand, as mentioned earlier, the combined genotype of either of these SNPs and c.975-71T > C - AADAT (rs1480544) may be associated with occurrence of depression $(p<0.05)$ (Table 3$)$.

The present study had some potential limitations. First of all, the sample size was relatively small and consequently of low power, which could lead to both false negative as well as false positive findings. Therefore these results should be interpreted with caution and considered preliminary. Second, the studied population was from Poland only, which reduces the possibility of confounding from ethnicity, so it does not permit any extrapolation of the results to other ethnic groups.

The findings of this work cast a new light on the pathogenesis of depression; however, some additional larger case-control studies on different population groups and functional experiments are necessary before the final resolution about/findings as to the role of the TRYCATs pathway in the development of this disease.

\section{Conclusion}

In the current work,we showed that the chosen four SNPs of genes involved in tryptophan catabolites pathway may influence the risk of depression occurrence. Therefore, these polymorphisms may be considered as independent depression markers.

\section{Conflict of interest}

None.

\section{Acknowledgment}

Source of support: This study was supported by the financing from a scientific research grant from the National Science Centre of Poland (no. UMO-2015/19/BNZ7/00410)

\section{Appendix A. Supplementary data}

Supplementary data associated with this article can be found, in the online version, at https://doi.org/10.1016/j.eurpsy.2018.05.001.

\section{References}

[1] WHO. Depression. http://www.who.int/mediacentre/factsheets/fs369/en/ (November). 2012.

[2] Reddy MS. Depression: the disorder and the burden. Indian J Psychol Med 2010;32(1):1-2.

[3] Iwata M, Ota KT, Duman RS. The inflammasome: pathways linking psychological stress, depression, and systemic illnesses. Brain Behav Immun. 2013;31:105-14.

[4] Gałecki P, Maes M, Florkowski A, Lewiński A, Gałecka E, Bieńkiewicz M. Szemraj Association between inducible and neuronal nitric oxide synthase polymorphisms and recurrent depressive disorder. J Affect Disord 2011;129 (1-3): 175-82.

[5] Maes M. Depression is an inflammatory disease, but cell-mediated immune activation is the key component of depression. Prog Neuro-Psychopharmacol Biol Psychiatry 2011;35(3):664-75.

[6] Maes M, Leonard BE, Myint AM, Kubera M, Verkerk R. The new '5-HT' hypothesis of depression: cell-mediated immune activation induces indoleamine-2, 3-dioxygenase, which leads to lower plasma tryptophan and an increased synthesis of detrimental tryptophan catabolites (TRYCATs), both of which contribute to the onset of depression. Prog Neuro Psychopharmacol Biol Psychiatry 2011;35:702-21.

[7] Maes M, Galecki P, Verkerk R, Rief W. Somatization, but not depression, is characterized by disorders in the tryptophan catabolite (TRYCAT) pathway, indicating increased indoleamine 2,3-dioxygenase and lowered kynurenine aminotransferase activity. Neuro Endocrinol Lett 2011;32(3):264-73.

[8] Clarke DM, Currie KC. Depression, anxiety and their relationship with chronic diseases: a review of the epidemiology, risk and treatment evidence. Med J 2009;190(7):S54-60.

[9] Grippo AJ. Mechanisms underlying altered mood and cardiovascular dysfunction: the value of neurobiological and behavioral research with animal models. Neurosci Biobehav Rev 2009;33:171-80.

[10] Preiss K, Brennan L, Clarke D. A systematic review of variables associated with the relationship between obesity and depression. Obes Rev 2013;14(11): 906-18.

[11] Hryhorczuk C, Sharma S, Fulton SE. Metabolic disturbances connecting obesity and depression Front. Neurosci 2013;7:1-14.

[12] Castanon N, Luheshi G, Layé S. Role of neuroinflammation in the emotional and cognitive alterations displayed by animal models of obesity. Front Neurosci 2016;9:1-14.

[13] Pan A, Keum N, Okereke OI, Sun Q, Kivimaki M, Rubin RR, et al. Bidirectional association between depression and metabolic syndrome: a systematic review and meta-analysis of pidemiological studies. Diabetes Care 2012;35(5):117180.

[14] Lin HY, Huang CK, Tai CM, Lin HY, Kao YH, Tsai CC, et al. Psychiatric disorders of patients seeking obesity treatment. BMC Psychiatry 2013;13:1.

[15] Chaves Filho AJM, Lima CNC, Vasconcelos SMM, de Lucena DF, Maes M, Macedo D. IDO chronic immune activation and tryptophan metabolic pathway: a potential pathophysiological link between depression and obesity. Prog Neuropsychopharmacol Biol Psychiatry 2017;S0278-5846(16):30345-51.

[16] Wigner P, Czarny P, Synowiec E, Bijak M, Białek K, Talarowska M, et al. Association between single nucleotide polymorphisms of TPH1 and TPH2 genes, and depressive disorders. J Cell Mol Med 2017;1-14, doi:http://dx.doi. org/10.1111/jcmm.13459.

[17] Hamon M, Blier P. Monoamine neurocircuitry in depressionand strategies for new treatments: prog. Neuropsychopharma-col Biol Psychiatry 2013;45:54-63.

[18] Hayaishi O. Properties and function of indoleamine 2,3-dioxygenase. ] Biochem 1976;79:13-21.

[19] Watanabe Y, Fujiwara M, Yoshida R, Hayaishi O. Stereospecificity of hepatic Ltryptophan 2,3-dioxygenase. Biochem J. 1980;189:393-405.

[20] MacKenzie CR, Worku D, Daubener W. Regulation of IDO-mediated bacteriostasis in macrophages: role of antibiotics and anti-inflammatory agents. Adv Exp Med Biol 2003;527:67-76. 
[21] Fujigaki H, Saito K, Fujigaki S, Takemura M, Sudo K, Ishiguro H, et al. The signal transducer and activator of transcription 1alpha and interferon regulatory factor 1 are not essential for the induction of indoleamine 2, 3-dioxygenase by lipopolysaccharide: involvement of p38 mitogen-activated protein kinase and nuclear factor-kappaB pathways, and synergistic effect of several proinflammatory cytokines. J Biochem 2006;139:655-62.

[22] Wichers MC, Maes M. The role of indoleamine 2,3-dioxygenase (IDO) in the pathophysiology of interferon-alpha-induced depression. J Psychiatry Neurosci 2004;29:11-7.

[23] Henry CJ, Huang Y, Wynne A, Hanke M, Himler J, Bailey MT, et al. Minocycline attenuates lipopolysaccharide (LPS)-induced neuroinflammation, sickness behavior, and anhedonia. J Neuroinflammation 2008;5:15-28.

[24] Moreau M, André C, O'Connor JC, Dumich SA, Woods JA, Kelley KW, et al. Inoculation of Bacillus Calmette-Guerin to mice induces an acute episode of sickness behavior followed by chronic depressive-like behavior. Brain Behav Immun 2008;22:1087-95.

[25] Gabbay V, Ely BA, Babb J, Liebes L. The possible role of the kynurenine pathway in anhedonia in adolescents. J Neural Transm 2012;119:253-60.

[26] Connor TJ, Starr N, O'Sullivan JB, Harkin A. Induction of indolamine 2, 3dioxygenase and kynurenine 3-monooxygenase in rat brain following a systemic inflammatory challenge: a role for IFN-gamma? Neurosci Lett 2008;441(1):29-34

[27] O'Connor JC, André C, Wang Y, Lawson MA, Szegedi SS, Lestage J, et al. Interferongamma and tumor necrosis factor-alpha mediate the upregulation of indoleamine 2,3-dioxygenase and the induction of depressive-like behavior in mice in response to bacillus Calmette-Guerin. J Neurosci 2009;29(13):4200-9.

[28] O'Connor JC, Lawson M, André C, Moreau M, Lestage J, Castanon N, et al. Lipopolysaccharide-induced depressive-like behavior is mediated by indoleamine 2, 3-dioxygenase activation in mice. Mol Psychiatry 2009;14(5):511-22.

[29] Launay M, Callebert J, Surget A, Belzung C, Barone PR. Peripheral and cerebral metabolic abnormalities of the tryptophan-kynurenine pathway in a murine model of major depression Behav. Brain Res 2010;210(1):84-91.

[30] Maes M, Verkerk R, Bonaccorso S, Ombelet W, Bosmans E, Scharpé S. Depressive and anxiety symptoms in the early puerperium are related to increased degradation of tryptophan into kynurenine, a phenomenon which is related to immune activation. Life Sci 2002;71(16):1837-48.

[31] Gabbay V, Klein RG, Katz Y, Mendoza S, Guttman LE, Alonso CM, et al. The possible role of the kynurenine pathway in adolescent depression with melancholic features. J Child Psychol Psychiatry 2010;51(8):935-43.

[32] Meier TB, Drevets WC, Wurfel BE, Ford BN, Morris HM, Victor TA, et al. Relationship between neurotoxic kynurenine metabolites and reductions in right medial prefrontal cortical thickness in major depressive disorder. Brain Behav Immun 2016;53:39-48.

[33] Savitz J, Drevets WC, Wurfel BE, Ford BN, Bellgowan PSF, Victor TA, et al. Reduction of kynurenic acid to quinolinic acid ratio in both the depressed and remitted phases of major depressive disorder. Brain Behav Immun 2015;46:55-9.

[34] Zoga M, Oulis P, Chatzipanagiotou S, Masdrakis VG, Pliatsika P, Boufidou F, et al. Indoleamine 2,3-dioxygenase and immune changes under antidepressive treatment in major depression in females. In Vivo 2014;28(4). . 633-538 http// :genome.UCSC.edu.

[35] Robinson CM, Shirey KA, Carlin JM. Synergistic transcriptional activation of indoleamine dioxygenase by IFN-gamma and tumor necrosis factor-alpha. J Interferon Cytokine Res 2003;23:413-21.

[36] Mellor AL, Munn DH. Tryptophan catabolism and T-cell tolerance: immunosuppression by starvation? Immunol Today 1999;20:469-73.

[37] Taylor MW, Feng GS. Relationship between interferon-gamma, indoleamine 2,3-dioxygenase, and tryptophan catabolism. FASEB J 1991;5:2516-22.

[38] Chon SY, Hassanain HH, Gupta SL. Cooperative role of interferon regulatory factor 1 and p91 (STAT1) response elements in interferon-gamma-inducible expression of human indoleamine 2,3-dioxygenase gene. J Biol Chem 1996;271:17247-52.

[39] Pertz H, Back W. Synthesis and resolution of chiral ring-opened serotonin analogs of the 5-hydroxykynuramine type. Pharmaceutica Acta Helvetiae 1988;63:128-38.
[40] Cryan JF, Leonard BE. 5-HT1A and beyond: the role of serotoninand its receptors in depression and the antidepressant response. Hum Psychopharmacol 2000;15:113-35.

[41] Lee S, Jeong J, Kwak Y, Park SK. Depression research: where are we now? Molecular Brain 2010;3:8.

[42] de Souza FR, Fontes FL, da Silva TA, Coutinho LG, Leib SL, Agnez-Lima LF. Association of kynurenine aminotransferase II gene C401T polymorphism with immune response in patients with meningitis. BMC Med Genet 2011;12:51.

[43] Stone TW, Darlington LG. Endogenous kynurenines as targets for drug discovery and development. Nat Rev Drug Discov 2002;1:609-20.

[44] Guillemin GJ, Kerr SJ, Smythe GA, Smith DG, Kapoor V, Armati PJ, et al. Kynurenine pathway metabolism in human astrocytes: a paradox for neuronal protection. J Neurochem 2001;78(4):842-53.

[45] Maes M, Mihaylova I, RuyterDe M, Kubera M, Bosmans E. The immune effects of TRYCATs (tryptophan catabolites along the IDO pathway): relevance for depression - and other conditions characterized by tryptophan depletion induced by inflammation. Neuro Endocrinol Lett 2007;28(6):826-31.

[46] Schlittler M, Goiny M, Agudelo LZ, Venckunas T, Brazaitis M, Skurvydas A, et al. Endurance exercise increases skeletal muscle kynurenine aminotransferases and plasma kynurenic acid in humans. Am J Physiol Cell Physiol 2016;310(10): C836-40.

[47] Heitzman J. Zaburzenia snu - przyczyna czy skutek depresji? Psychiatr Pol 2009;XLIII(5):499-511.

[48] ICD-10. International Statistical Classification of Diseases and Related Health Problems 10th Revision (ICD-10). Genewa: World Health Organization; 2015.

[49] Hamilton M. A rating scale for depression. J Neurol Neurosurg Psychiatry $1960 ; 23: 56-62$.

[50] Demyttenaere K, De Fruyt J. Getting what you ask for: on the selectivity of depression rating scales. Psychothery Psychosom 2003;72:61-70.

[51] Kessler RC. Epidemiology of women and depression. J Affect Disord 2004;74:5-13.

[52] Han Q, Cai T, Tagle DA, Li J. Structure, expression, and function of kynurenine aminotransferases in human and rodent brains. Cell Mol Life Sci 2010;67 (3):353-68.

[53] Moore LE, Boffetta P, Karami S, Brennan P, Stewart PS, Hung R, et al. Occupational trichloroethylene exposure and renal carcinoma risk: evidence of genetic susceptibility by reductive metabolism gene variants. Cancer Res 2010;70(16):6236-527.

[54] Jacobson A, Peltz SW. Interrelationships of the pathways of mRNA decay and translation in eukaryotic cells. Annu Rev Biochem 1996;65:693-739.

[55] Decker CJ, Parker R. Mechanisms of mRNA degradation in eukaryotes. Trends Biochem Sci 1994;19(August (8)):336-40.

[56] Kralovicova J, Vorechovsky I. Global control of aberrant splice-site activation by auxiliary splicing sequences: evidence for a gradient in exon and intron definition. Nucleic Acids Res 2007;35:6399-413.

[57] Dai W, Gupta SL. Molecular cloning, sequencing and expression of human interferon-gamma-inducible indoleamine 2, 3-dioxygenase cDNA. Biochem Biophys Res Commun 1990;168(1):1-8.

[58] Najfeld V, Menninger J, Muhleman D, Comings DE, Gupta SL. Localization of indoleamine 2,3-dioxygenase gene (INDO) to chromosome 8 p12-> p11 by fluorescent in situ hybridization. Cytogenet Cell Genet 1993;64(3-4):231-2.

[59] Munn DH, Mellor AL. Indoleamine 2,3 dioxygenase and metabolic control of immune responses. Trends Immunol 2013;34(3):137-43.

[60] Prokunina L, Alarcón-Riquelme ME. Regulatory SNPs in complex diseases: their identification and functional validation. Expert Rev Mol Med 2004;6 (April (10)):1-15.

[61] Marsh S. Pharmacogenomics. Ann Oncol 2007 ix24-ix28.

[62] Roden DM, Altman RB, Benowitz NL, Flockhart DA, Giacomini KM, Johnson JA, et al. Pharmacogenetics research network. pharmacogenomics: challenges and opportunities. Ann Intern Med 2006;145(November (10)):749-57.

[63] Galvão-de Almeida A, Quarantini LC, Sampaio AS, Lyra AC, Parise CL, Paraná R, et al. Lack of association of indoleamine 2,3-dioxygenase polymorphisms with interferon-alpha-related depression in hepatitis C. Brain Behav Immun 2011;25(7):1491-7. 